\title{
Rethinking the actor in service research: toward a processual view of identity dynamics
}

\author{
Kaisa Koskela-Huotari \\ CTF, Service Research Center, Karlstad University, Karlstad, Sweden, and \\ Jaakko Siltaloppi \\ Department of Industrial Engineering and Management, \\ Aalto University School of Science, Espoo, Finland
}

Rethinking the actor in service research

Received 2 January 2019

Revised 28 June 2019

25 November 2019

Accepted 3 December 2019

\begin{abstract}
Purpose-Only a few concepts in the service literature are as pervasive yet as undertheorized as is the concept of the actor. With a growing interest toward value creation as a systemic and institutionally guided phenomenon, there is a particular need for a more robust conceptualization of humans as actors that adopts a processual, as opposed to a static, view. The purpose of this paper is to build such processual conceptualization to advance service-dominant (S-D) logic, in particular, and service research, in general.

Design/methodology/approach - The paper is conceptual and extends S-D logic's institutionally constituted account of the actor by drawing from identity theory and social constructionism.

Findings - The paper develops a processual conceptualization of the human actor that explicates four social processes explaining the dynamics between two identity concepts - social and personal identity-and institutional arrangements. The resulting framework reveals how humans are simultaneously constituted by institutions and able to perform their roles in varying, even institution-changing, ways.

Research limitations/implications - By introducing new insights from identity theory and social constructionism, this paper reconciles the dualism in S-D logic's current description of actors, as well as posits the understanding of identity dynamics and the processual nature of actors as central in many service-related phenomena. Originality/value - This paper is among the few that explicitly theorize about the nature of human actors in S-D logic and the service literature.
\end{abstract}

Keywords Actor, Processual view, Social identity, Personal identity, Identity dynamics, Institutional arrangements, Roles, Service-dominant logic

Paper type Conceptual paper

\section{Introduction}

While service providers, customers, and frontline service employees are commonly discussed in service research, the literature is relatively silent on the nature of the underlying assumptions it makes about these actors[1] from a theoretical point of view. In fact, few concepts in the service literature are as pervasive yet as undertheorized as is the actor. Actors are everywhere in the descriptions and analyses of service encounters, processes, quality, and innovation, but they are rarely explored beyond a superficial recognition of the few aforementioned roles. Moreover, the growing interest toward the role of technology, such as robots and artificial intelligence (AI), in

(C) Kaisa Koskela-Huotari and Jaakko Siltaloppi. Published by Emerald Publishing Limited. This article is published under the Creative Commons Attribution (CC BY 4.0) licence. Anyone may reproduce, distribute, translate and create derivative works of this article (for both commercial \& non-commercial purposes), subject to full attribution to the original publication and authors. The full terms of this licence may be seen at http://creativecommons.org/licences/by/4.0/legalcode

This paper forms part of a special section "The Naples Forum on Service", guest edited by Cristina Mele and Francesco Polese.

The authors wish to thank the participants of the 2017 Naples Forum on Service and the two anonymous reviewers for their valuable feedback to the earlier drafts of this paper. Kaisa Koskela-Huotari was supported by Jan Wallander and Tom Hedelius foundation research grant (W18-0013).

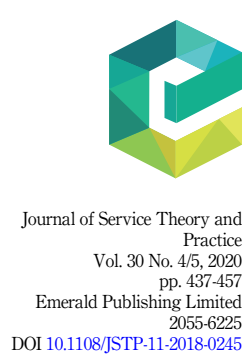


JSTP

$30,4 / 5$

438 service interactions (e.g. Caić et al., 2018; Robinson et al., 2019; Wirtz et al., 2018) calls for a more thorough conceptualization of humans as actors in order to critically examine the differences and similarities between human and nonhuman actors.

In this paper, we dig deeper into the concept of the actor to provide a fuller theoretical grounding for thinking about human actors in the context of service research. We show how the view on actors has gradually extended over time from firms to customers and beyond. However, much of prior work continues to focus on the provider-customer dyad, which limits its applicability in conceptualizing the actor at a more general level. Because of this, we specifically align this treatise of the actor with the service-dominant (S-D) logic discussion, which moves beyond the provider-customer dyad in developing a metatheoretical account of value creation in service ecosystems (e.g. Vargo and Lusch, 2004, 2011; 2016). S-D logic advocates a view in which all actors fundamentally do the same things-integrate resources and engage in service exchange in the process of cocreating value. This view replaces the centrality of the producer and customer roles predominating the service literature with a systemic view of the interlinked, resource-integrating actors engaged in collaborative value creation. Furthermore, the recent literature in S-D logic emphasizes the role of institutional arrangements as "the keys to understanding human systems and social activity, such as value cocreation" (Vargo and Lusch, 2016, p. 11). This emerging view of value creation as a systemic and institutionally guided phenomenon calls for a processual, rather than a static, conceptualization of individual humans as actors.

Despite its axiomatic status in S-D logic, the resource-integrating actor has not, however, received much detailed discussion and analysis to date (for notable recent exceptions, see Polese et al., 2017 and Tronvoll, 2017). In part, we suspect that this is due to the metatheoretical nature of S-D logic, which has produced a rather abstract notion of the actor as a resource integrator. We also locate a dualism in the description of the actor in S-D logic, which has further complicated the issue: on the one hand, the actor is portrayed as an institutionally constituted resource integrator and a collection of (operant) resources; on the other hand, the actor is conceived as a unique, value-experiencing, and value-defining beneficiary.

In light of these issues, the purpose of this paper is to advance the conceptualization of human actors within S-D logic, in particular, and in service research, in general. Distinct from recent studies that explore the actor as a part of the service ecosystems perspective (Tronvoll, 2017; Polese et al., 2017), we draw from identity theory (e.g. MacKinnon and Heise, 2010) and social constructionism (Berger and Luckman, 1967) to develop a processual conceptualization of the human actor as both constituted by the institutional arrangements that surround her and a purposive actor enacting value cocreation roles in particular and potentially novel ways based on her personal identity. We develop this argument by elaborating the following four processes: (1) the institutional constitution of social identities and roles, (2) the development of personal identity through the internalization of multiple social identities, (3) the actualization of personal identity through role enactment, and (4) institutional reproduction and change through role performances.

With this work, we make the following contributions to advance the understanding of actors in S-D logic, in particular, and in service research, in general. First, we extend the institutionally constituted account of the actor within S-D logic and reconcile the two views of the actor that emerge from its foundational premises; we do so by building a processual framework of the dynamics between the two identity concepts - social and personal identity - and institutional arrangements. Second, we bring roles back into service research and position them as a key construct in understanding several service-related phenomena; we do so by highlighting roles and their associated social identities as the mediator between institutional arrangements and the unique personal identities that enable individuals to perform the social roles in distinct ways. Third, by incorporating the two new identity concepts into the conceptualization of the actor, our work outlines two distinct dynamics for institutional change within service ecosystems. 
In the following, we first review service research and discuss how the conceptualization of the actor has gradually evolved. We point out that although the view on actors has broadened over time, specifically through the metatheoretical narrative of S-D logic, inconsistencies and unanswered questions remain regarding the nature of human actors. Second, we build a processual conceptualization of the human actor by explicating four analytically distinct social processes. More specifically, we argue that the actor can be understood through the dynamics between institutional arrangements, social identities, and personal identity; we show how this reconceptualization is aligned with S-D logic's institutional understanding of value cocreation. Finally, we discuss the implications of our conceptualization for service research and provide guidance for future research.

\section{Existing portraits of the actor in service research}

Although service research has traditionally held a rather narrow view of the actor as firms, this view has significantly broadened over time. In the following, we review the existing portraits of the actor within service research to problematize and build on the ways prior research has theorized about the actor.

\section{From firms to customers and beyond}

At first, service research was mainly focused on firms as the active actors in the service production process. According to Parasuraman et al. (1985), early service research, such as marketing literature more broadly, considered the firm (or the service provider) as the main focal actor whose actions determined the success of service situations. However, because of the special characteristic of services - often being produced simultaneously as they are consumed-services marketing rather quickly began to highlight also the role of the customer in services. An early pioneer in service quality research, Christian Grönroos (1984), for example, argued that the concept could be divided into technical quality - what the customer received from the service-and functional quality - the manner in which the service is delivered. In this division, he emphasized that service is delivered in interaction with the customer, so how the customer acts and thinks also influences the perceived outcome of the service interaction. The dyadic view of service actors was further elaborated by the definition of the service encounter as a dyadic and reciprocal human interaction (Solomon et al., 1985), which led to the further acknowledgment of the customer as a prominent actor in service research. More specifically, Solomon et al. (1985) argued that both the service provider and customer are important determinants of satisfaction with the encounter.

Over time, the conception of customers as actors has further expanded; from being mere evaluators of service quality and satisfaction, customers have been perceived as participants in producing the service (Williams and Anderson, 2005) and, more generally, as a part of value cocreation processes (Prahalad and Ramaswamy, 2004; Lusch and Vargo, 2006). For example, they have been acknowledged as sources of innovative ideas and active participants in the service development process (e.g. Alam, 2002; Oliveira and von Hippel, 2011). More recently, attention has expanded beyond customer collaboration toward a networked, multiactor view of value creation in service contexts. In particular, advocates of S-D logic argue for a more systemic understanding of value cocreation that includes the move to zoom out from individual actors or dyads as main unit of analysis and the acknowledgment of the role and participation of numerous actors, organized into collectives and systems, within value cocreation (Lusch and Vargo, 2014; Vargo and Lusch, 2011). This development has led to calls for research from a multiactor perspective, for example, in service innovation (Rajala et al., 2016) and customer engagement (Alexander et al., 2018).

Hence, the research scope has expanded from producers alone to a complex array of human actors playing different roles in the value creation process. Most recently, service
Rethinking the actor in service research 
JSTP

$30,4 / 5$

440

research has started to grapple with the idea of nonhuman actors as service providers, focusing especially on service robots as actors in the service process (Caic et al., 2018; Wirtz et al., 2018). So far, the primary focus has been on how technologies may replace human actors as service providers. For example, Wirtz et al. (2018) compared service robots with frontline employees, concluding that robots work best in complex cognitive-analytical tasks, whereas human employees perform better in complex emotional-social tasks with significant variance. However, the current comparisons of human and nonhuman actors remain at a rather surface level. One explanation for this tendency might be the lack of a detailed conceptualization of a human actor in service research that would allow the more thorough examination of the foundational differences (and similarities) between human beings and technology as actors at a higher level of abstraction. Studies taking a role theory approach on actors represent a rare exception to this inclination of retaining actors as conceptual black boxes in service research.

\section{The actor as a role performer in service interactions}

In the 1980s, the concept of role represented one of the most popular ideas in the social sciences (Biddle, 1986). Role theory provided a perspective for studying various social phenomena and was also applied in services marketing; in this field, it was found particularly useful for opening new perspectives to theorizing the service encounter, defined as the "faceto-face interactions between a buyer and a seller in a service setting" (Solomon et al., 1985, p. 100). Solomon et al. (1985) emphasized that because service encounters are fundamentally about dyadic, reciprocal human interactions, marketers should abandon the static view of the consumer and acknowledge that both the service provider and the customer play a significant role in shaping the interaction and evaluation of its outcomes. Drawing from role theory, Solomon et al. (1985) argued that each actor in service encounters has learned a set of behaviors - a script - that is appropriate for a specific situation with certain roles. In other words, role theory argues that the behavior of two people in a service interaction is principally determined by the roles they adopt (Broderick, 1998).

Thus, in the role theoretical approach in service research, the individuals taking part in a service encounter are viewed as "social actors who learn behaviors appropriate to the positions they occupy in society" (Solomon et al., 1985, p. 102). According to Solomon et al. (1985), one important consequence of this socialization into a role is the ability to predict the behavior of other actors in their roles. These predictions are based on expectations for behavior implied in learned scripts. As an actor's behavior in enacting a role is always interdependent with the behavior of other actors enacting complementary roles, service scripts contain information about the expected behavior of oneself and of others and reflect an individual's learned (or imagined) conception of the prototypical service experience.

According to Broderick (1998), service roles are dynamic because actors adopt and modify roles through a continuous process. Therefore, role development is an important aspect to consider in any medium- to long-term service relationships (Broderick, 1998). Similarly, Solomon et al. (1985) acknowledged that scripts are only partially shared and can change over time, although resistance exists especially in the case of radical changes in the roles and associated scripts. Furthermore, taken-for-granted service scripts enable the minimization of cognitive activity in everyday situations. However, even though the role theoretical approach has gained some traction (e.g. the theater perspective on service interactions derived from role theory is often recalled), the further development of the approach into a full-fledged theory of actors in service research has not progressed apart from a few notable exceptions (see e.g. Akesson, 2011). In light of the recent turn to a systemic view of value creation, one reason for this may be the narrow focus of role-based accounts on the provider-customer dyad; this limits the applicability of role-theoretical insights in conceptualizing the actor at a more general level. 
The actor in the axioms and the foundational premises of S-D logic

The generic, systemic view of actors as value creators is most evident in S-D logic, which provides a metatheoretical scaffolding for understanding value cocreation in service ecosystems. The starting point for understanding the actor within S-D logic is the rejection of the producer-consumer divide that is prevalent in mainstream marketing. Instead of assigning one group of actors with the static and permanent role of a value creator (producer) and the other group with the role of a value destructor (consumer), S-D logic advocates an inherently symmetric view of all actors as resource integrators (Vargo and Lusch, 2011). This actor-to-actor (A2A) view highlights that all actors are fundamentally engaged in the same activity, integrating resources and exchanging service in the process of cocreating value. The process of resource integration is collaborative by nature. According to Vargo and Lusch (2016), value is always cocreated by multiple actors, which means that a single actor cannot deliver value but can only participate in the creation and offering of value propositions.

This fundamentally intersubjective view of resource integration as a collaborative and knowledge-driven process (Peters et al., 2014) implicitly conceptualizes the actor as a constellation of her (operant) resources. Because actors are first and foremost resource integrators, their operant resources are what enables them to take part in value cocreation with others. However, the view of the actor as a constellation of resources is not static. Resources are constantly modified and created through networked resource integration processes, and as reflexive and knowledgeable learners (Peters et al., 2009), human actors acquire new knowledge and skills. When these are integrated with the resources held by or available through other actors, the creation of new resources changes both the actors and the contexts of their value cocreation efforts (Chandler and Vargo, 2011). Thus, resources do not have intrinsic value nor objective existence but instead gain their existence and value from other resources with which they are integrated in the process of value cocreation. For example, a hammer is a much more valuable (and relevant) resource at a construction site than in the process of academic writing (although sometimes, integrating a hammer with a laptop might temporarily alleviate the frustrations caused by a lack of progress)[2].

S-D logic also increasingly emphasizes the embeddedness of actors in institutions and institutional arrangements that guide, constrain, and coordinate collective value cocreation efforts (see Vargo and Lusch, 2016). Institutions are the shared and largely taken-for-granted rules, norms, values, and meanings that, together with the associated activities and resources, provide stability and meaning to social life (Scott, 2014). In this view, institutions guide and constrain actors in making sense of and using resources for value creation (Koskela-Huotari and Vargo, 2016); this underscores the point that resources (and, consequently, actors as constellations of resources) gain their meaning from the institutional contexts they are a part of. Therefore, actors and their engagement in resource integration and service exchange must always be considered within their institutional context, in which the actors gain their ability to act through the resources they hold in the context of other available resources (see also Chandler and Vargo, 2011).

The conceptualization of the actor as a constellation of institutionally defined resources is not the sole view of the actor in S-D logic. S-D logic also emphasizes the unique and phenomenological determination of value by the beneficiary, that is, that each actor individually participates in and experiences the benefits of value cocreation (Vargo and Lusch, 2008). This portrays the actor as a conscious and experiencing person capable of determining the value of surrounding events uniquely based on her subjective evaluation that draws on past experiences, the current situation, and imagined futures. This view of the actor remains bound within the institutions and institutional arrangements of the surrounding ecosystem, which frame the actor's unique personal experiences in a sociohistorical context and its interpretive framework (Akaka et al., 2015). However, the emphasis is clearly on the unique, subjective, and phenomenological side of what it means to be an actor, acknowledging both the
Rethinking the actor in service research 
JSTP

$30,4 / 5$ intrasubjective (i.e. personal/psychological) and intersubjective (i.e. social) processes (Helkkula et al., 2012) that define the human actor.

Taking stock, S-D logic therefore has two interrelated yet distinct views on the actor-one depicting the actor as a constellation of resources, and the other as a unique, experiencing person. Hence, the challenge for the subsequent account is to develop a conceptualization that simultaneously accounts for the processual and institutional constitution of the resourceintegrating actor, as well as the conscious person that makes decisions and uniquely experiences and determines the value of events.

\section{Reconceptualizing the actor through identity dynamics}

To extend the role-theoretical accounts of actors in service research and to reconcile the dualism of the actor as captured in S-D logic, we build a processual conceptualization of the human actor. As explained in Table I, we ground our conceptualization on S-D logic's existing institutional understanding of value cocreation as guided and constrained by institutional arrangements (Vargo and Lusch, 2016), which draws on both structuration theory (Giddens, 1984) and institutional theory stemming particularly from organizational studies (e.g. Scott, 2014). We augment this institutionally constituted account of the actor by drawing further insights from identity theory (e.g. MacKinnon and Heise, 2010) and the social constructionism of Berger and Luckman (1967). These theories share their focus on the creation and maintenance of social worlds through repeated interactions between individuals and specifically how individuals are both the products and producers of socially constructed meanings. Within identity theory, we are particularly close to structural symbolic interactionists, who, drawing on Mead's (1934) seminal work, use identity to refer to the meanings that individuals attach to the roles they play in different contexts (e.g. Owens et al., 2010; Stryker, 2008). Such meanings are embedded in institutional arrangements and internalized by individuals as a basis of their selfunderstanding (MacKinnon and Heise, 2010). In addition, we draw on Berger and Luckman's (1967) treatise on the social construction of reality to highlight the importance of social interactions and socialization processes; through these, individuals internalize the institutionalized norms, values, and assumptions associated with the roles they play, which subsequently shape their self-understandings and social behavior. Both of these theories are aligned with the institutional understanding of S-D logic as they provide useful insights in detailing the social processes connecting individuals and institutional arrangements in a mutually constitutive relationship.

This conceptual grounding enables us to distinguish four specific processes that straddle the institutional, social group, and individual levels of analysis, as visualized in Figure 1. In this account, we seek to avoid the generic notion of the actor and instead discuss the constitutive processes through which the institutional sphere influences the formation and reformation of the individual through the roles she plays across the contexts of her life. We begin this account with an institutional understanding of social action in which individuals are guided by largely taken-for-granted institutional arrangements that enable and constrain their action (Scott, 2014; Vargo and Lusch, 2016). Importantly, we augment this view by introducing two identity concepts. First, we use the concept of social identity to elaborate the centrality of situated social interactions in which institutionalized social roles guide and constrain the behavior of interrelated individuals. Specifically, we define social identity as an institutionalized self-conceptualization specific to a role, which an individual uses to make sense of oneself and of others as actors in a particular context. Second, we use the concept of personal identity to discuss the unique person behind the multiple value cocreation roles and social identities enacted by an individual. In our use, personal identity refers to the enduring yet evolving self-understandings developed through the internalization of role-specific self- 


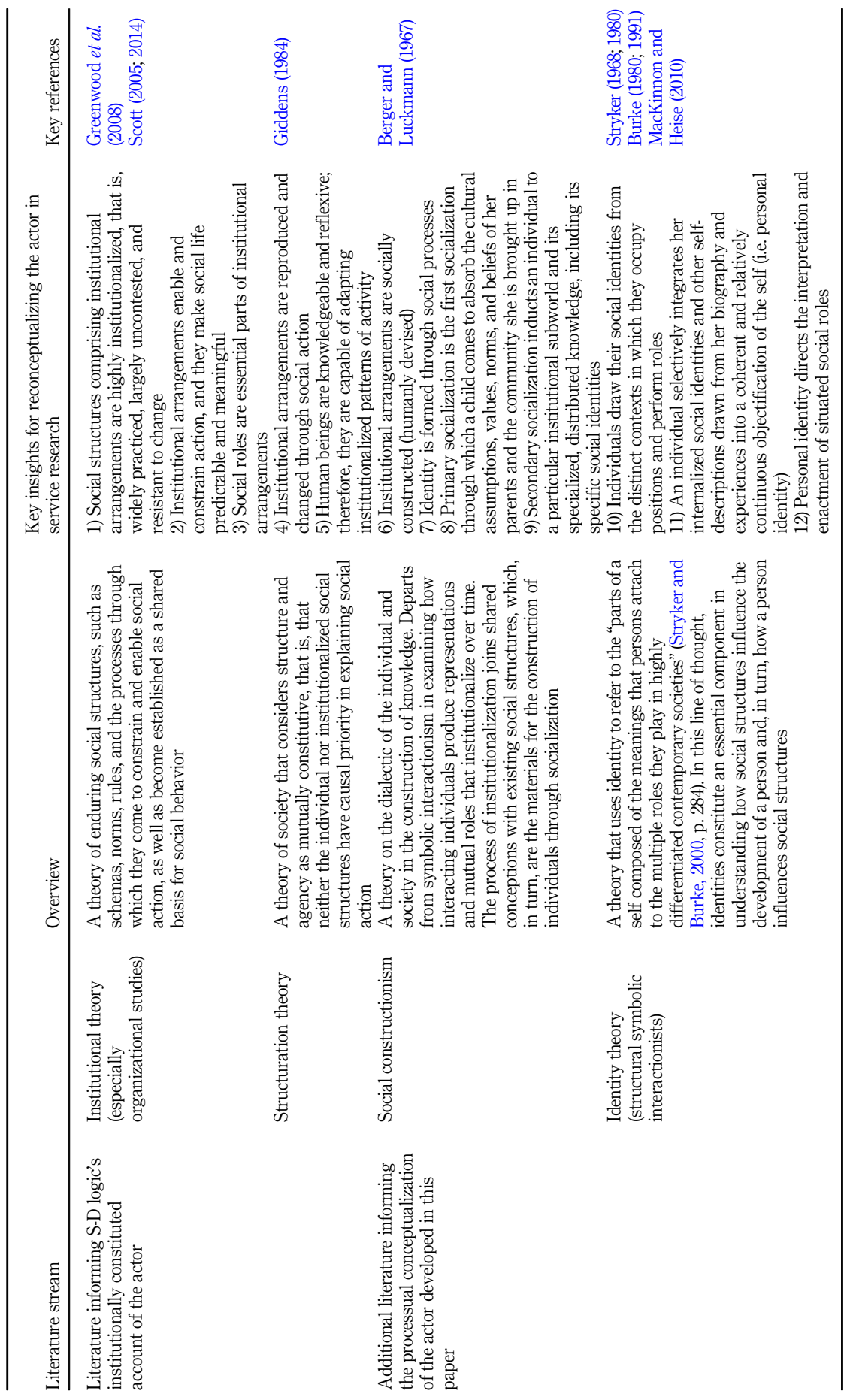

Rethinking the actor in service research

443

Table I. Literature streams integrated in the processual conceptualization of the actor 
JSTP

$30,4 / 5$

\section{4}

Figure 1.

Actor

conceptualization through four social processes

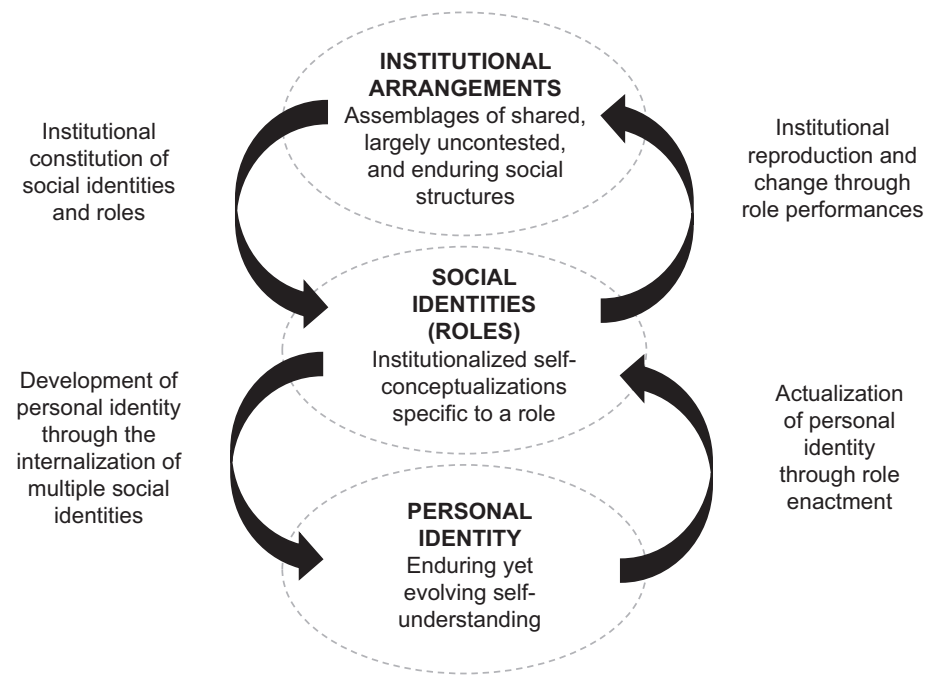

conceptualizations, which direct the way in which an individual sees oneself as a person and performs one's roles across the multiple contexts of one's life.

Further, we discuss the processual conceptualization of the human actor in four sections. First, we present how institutional arrangements constitute social settings by specifying the available and appropriate social roles and associated social identities. Second, we detail how a personal identity develops via the internalization of multiple social identities through primary and secondary socialization. Third, we explicate how personal identity directs individuals' role-taking and self-actualization in social performances. Finally, we bring the account back to the institutional sphere by discussing the essential role of identity dynamics in the reproduction and change of institutional arrangements.

\section{The institutional constitution of social identities}

As pointed out earlier, institutional arrangements are assemblages of humanly devised rules, norms, values, beliefs, and other social structures that enable and constrain action and make social life predictable and meaningful (Vargo and Lusch, 2016; see also Scott, 2014). As social structures, institutional arrangements are highly institutionalized, that is, widely shared, enduring, and largely uncontested (Greenwood et al., 2008). Importantly, they are not exogenous to actors but reproduced by them through relatively self-activating processes (Cardinale, 2018). This view is acknowledged in S-D logic by viewing institutional arrangements through Giddens' (1984) structuration theory. According to this theory, structure and agency are mutually constitutive, that is, that neither the individual nor institutionalized social structures have causal priority in explaining social action. This means that while institutional arrangements provide the rules of the game (North, 1990) for social action, they are reproduced and changed through the very enactment of social action (Giddens, 1984).

The institutional view of S-D logic thus positions human beings within socially constructed institutional arrangements (Berger and Luckmann, 1967) that guide and constrain them, but which are also available for them to modify and change (Friedland and Alford, 1991; Thornton et al., 2012). An essential part of institutional arrangements is the social roles that structure social interactions by embodying specific understandings, expectations, and scripts (Scott, 2014). For the individual, institutional arrangements offer 
specific institutionalized meanings or categories that are specific to the roles in the social setting (Stryker and Burke, 2000). We refer to such meanings as social identities and define them as the institutionalized self-conceptualizations that are specific to a role. As such, the individual uses social identities to make sense of herself and of others as actors in a particular social context (MacKinnon and Heise, 2010).

As institutionalized meanings or categories, social identities can be very broad and general, for example, when based on traits, such as gender, race, or nationality; they can also be very specific and situated, for example, in professional contexts, such as academia, which distinguishes between highly specialized and interrelated roles (e.g. full and assistant professors, lecturers, adjuncts, teaching assistants, post-docs, doctoral students). As we will discuss later on, social identities are not static, but they evolve through social action. However, before discussing this point in more detail, we need to understand the relationship between social identities, as specific to roles, and individuals, as unique persons who internalize social identities as a part of their personal identity.

\section{The development of personal identity through the internalization of multiple social identities}

Although social identities and, more broadly, institutions, can be understood as resources that are available to individuals in a context, they are only accessible through participation in social interactions with others (e.g. Thornton et al., 2012). Indeed, an individual acquires knowledge about the social identities and routinized activities associated with specific roles through participation in a value-creating community (e.g. Lave and Wenger, 1991). Theorized by Berger and Luckman (1967), individuals acquire practical knowledge about specific contexts of action through socialization. According to Berger and Luckman, socialization is about the retrojection of the objectified (i.e. institutionalized) social world into the consciousness of an individual. It is a gradual, participatory process through which an individual becomes acquainted with the social world of specific others by interacting with them, learning about their subjective processes and behaviors to the extent that these become meaningful and hence a basis for participating in interactions with others in the future. For example, one is not born with or does not come to master the role of a customer by reading economics textbooks; it occurs through practicing this role in real-life exchange situations with others, such as one's parents and peers early on and later guided by service providers' personnel.

In essence, socialization is the gradual process through which institutions constitute actors (Berger and Luckman, 1967). Individuals, through reflexive participation, learn the routines and skills needed for performing a role, as well as develop an understanding of how to act with and in relation to others in order to cocreate value. An important part of socialization is the internalization of a particular social identity. All social roles and identities are not typically available to all actors, as social settings involve traditions and hierarchies that assign newcomers to specific roles, for example. Moreover, role-taking unfolds through a social process in which the participants individually and collectively evaluate the behaviors of others and compare their behaviors against the expectations of the group, adjusting their behavior accordingly (MacKinnon and Heise, 2010).

Furthermore, the socialization process is not limited to the acquisition of situated social identities but entails the ongoing (re-)formation of the individual's personalidentity. Specifically, we use personal identity to refer to the enduring yet evolving self-understandings developed through the internalization of role-specific self-conceptualizations. Akin to Mead's (1934) notion of the objectified $m e$ (in distinction to the experiencing $I$ ), personal identity consists of all the learned perspectives and assumed attitudes a person takes toward herself (Owens et al., 2010) across the many social contexts the person is a part of in a modern society (Giddens, 1991). Importantly, personal identity is not simply a sum of social identities; it entails a fusion of internalized social identities into a unique, continuous, and relatively enduring conception of self-a biographical narrative (MacKinnon and Heise, 2010) with which the individual 
JSTP

$30,4 / 5$

446

constructs and maintains a coherent self-understanding from the past to the future through the present (Giddens, 1991). As such, personal identity directs the way in which the individual sees herself as a person and performs her roles across the multiple contexts of her life.

Despite being more enduring, a personal identity evolves through the same socialization processes through which individuals adopt and modify their context-specific social identities. In contrast to the formation and evolution of specific social identities, however, the formation and evolution of personal identities are typically slower and more nuanced because they are influenced by the multiple socialization processes over the course of an individual's life. Moreover, the personal identity already formed constitutes the basis for the subsequent identity formation process (McCall and Simmons, 1966; Owens et al., 2010). Berger and Luckman (1967) provide a useful distinction by emphasizing primary socialization as the process that significantly shapes the personal identity of an individual. Primary socialization is the first socialization an individual experiences in childhood; it is based on a strong emotional attachment to one's caregivers, through which the child comes to absorb the cultural assumptions, values, norms, and beliefs of her parents and the community she is brought up in. In this sense, primary socialization creates the basic self-conceptions that are, by nature, more enduring than the situated, role-specific social identities learned later on in life. This is not to say that the processes of secondary socialization do not carry any impact on personal identity. As discussed by Berger and Luckman (1967), secondary socialization inducts an individual to a particular institutional subworld and its specialized, distributed knowledge, including its specific social identities. As the social identities accumulate over time and across contexts, these leave an imprint on an individual's personal identity; this perhaps particularly occurs in cases in which roles and social identities play an important part in a person's life (e.g. work identities, identity as a parent).

\section{The actualization of personal identity through role enactment}

In this sense, to perform a role means not only to learn the routines and skills necessary for resource integration but also to be aware of oneself as a particular kind of actor, that is, an individual enacting a social role directed by her personal identity in a specific context. With the concepts of social and personal identity, we can clarify this distinction by simultaneously explicating how individuals adopt and enact social identities specific to their social contexts, as well as how they do so in unique and personal ways guided by their personal identity. Agreeing with Padgett and Powell (2012), we conceptualize individuals as role ensembles who nevertheless have values, goals, and principles that anchor a unique and enduring understanding of their personal self, which is distinct from the specific roles they play.

The separation of personal identity from role-specific social identities is useful, as it enables us to tease out differences among individuals (and collectives) in performing particular roles. Here, personal identity can be understood as providing individuals with certain overarching values and principles that direct the roles they adopt, as well as the way in which they perform these roles and personify associated social identities (e.g. Tsushima and Burke, 1999). Peters (2012) makes a similar point in her discussion of the customer. For her, customers, as actors, "not only assume a social role within the value cocreation process but also personify it in a particular way as a unique person" (p. 134). Drawing on Archer (1995), Peters distinguishes between the institutionally constituted roles that structure action in a context, on the one hand, and the capacity of an individual to perform a role in a particular and personal way, on the other hand. For example, while some individuals may perform the role of a customer in a temperate, polite manner, others perform it in a more abrasive and demanding way with possibly different outcomes.

Hence, we highlight that the ability of individuals to partake in resource integration and service exchange originates in the adoption and enactment of social roles, as well as in the application of resources that the roles afford access to (e.g. Bourdieu, 1990). In this sense, the 
various roles and associated social identities are a resource through which individuals engage in value cocreation (Akaka and Chandler, 2011). The personal identity, however, is not so much a resource for individuals as it is an imperative; it directs a person to seek out specific roles over others and to perform them in a particular way in order to actualize her deeply held conception of the self (MacKinnon and Heise, 2010). Indeed, individuals seek to actualize their personal identities through role performances, inducing fluctuation, variance, and conflict into social situations. As we will discuss next, these dynamics play a crucial role in the reproduction and change of existing institutional arrangements.

\section{Institutional reproduction and change through role performances}

The fourth and final process connects the personal and social identity dynamics back to the institutional arrangements, with which we began our discussion. As mentioned, S-D logic follows Giddens' (1984) view that institutional arrangements and human action are mutually constitutive, that is, that neither the individual nor the social structure has primacy in explaining human action. Our preceding account deepens this view by explicating how human beings are simultaneously the products of institutional arrangements, shaped through processes of socialization, and the producers of social realities through situated interactions and role performances in which they seek to actualize their personal identities (cf. Berger and Luckmann, 1967). This idea directs us to the final part of our argument that pertains to institutional reproduction and change.

In the simplest case, the social identities and routinized activities of a given context are shared to a significant extent among participants. The personal identities of involved individuals also align with or are overridden by situational demands and social identities to the extent that social action primarily gears toward reproducing the existing institutional arrangement. Perhaps particularly when supported by clear regulative constraints and strict social norms, as, for example, in the case of air traffic control towers or military aircraft carriers, institutional reproduction unfolds, as strong social identities and narrowly defined routine performances reduce the impact of personal identity on the unfolding of collective action. However, the example of the air traffic control tower also accentuates how institutional reproduction is not a mindless performance but is a conscious and, in many cases, demanding task (e.g. Farjoun, 2010). As emphasized by Giddens (1984), the knowledgeability and reflexive capacity of human beings allow them to access, adapt, and modify the institutionalized elements in situational contingencies in order to achieve or maintain stability in coordinated efforts to achieve collective goals.

Outside the specific case of tightly regulated and/or high-reliability contexts, our account of identity dynamics enables a closer analysis of two distinct mechanisms that underpin institutional reproduction and change. First, it is clear in contemporary society that an individual is not embedded in only one clearly defined institutional arrangement, in which she plays a more or less stable role throughout her life (as may have been, to some extent, the case in premodern communities). Instead, one has to manage multiplesometimes contradictory-social identities and resource integration practices associated with different institutional arrangements (e.g. Giddens, 1991; Holland et al., 1998; see also Vargo and Lusch, 2016). As such, an individual carries a collection or set of social identities internalized over her whole lifespan, which, along with the skills and other resources acquired through specific roles, is available to her in future interactions (MacKinnon and Heise, 2010; see also Swidler, 1986). Perhaps particularly in situations characterized by conflicting expectations and assumptions, individuals can recombine the symbolic and material resources available to them through multiple contexts into solutions that resolve the contradictions (MacKinnon and Heise, 2010; Siltaloppi et al., 2016). Such solutions may not only reproduce the existing roles, identities, and material practices but also alter them through social interaction (MacKinnon and Heise, 2010), with

Rethinking the actor in service research 
JSTP

$30,4 / 5$

448 a potential for wider institutionalization into the fabric of the service ecosystem (Berger and Luckman, 1967).

Second, our conceptualization of the actor emphasizes an additional locus of institutional reproduction and change by separating the personal identity from the various situated social identities. Specifically, the personal identity of individuals plays a central role in providing the motivational basis for them to seek out specific roles and perform them in particular ways. For example, we, academics, enjoy quite a significant leeway in performing our roles and pursuing our objectives in an autonomous and personalized manner. In such settings, the impact of personal identities on the variance and change in social practice may be larger because individuals seeking to actualize their personal identities with specific aspirations and orientations are more easily able to introduce new ways of performing and conceptualizing the roles in question (e.g. Tsushima and Burke, 1999). As such, personal identities may underpin institutional change by motivating individuals, as actors, to perform their roles differently. However, this variance does not lead to institutional change unless the perceived structure and understanding of shared social action are altered in a wider group (e.g. Feldman and Pentland, 2003). For institutional change to happen, the aspirations of specific individuals must be accepted and adopted by others, emphasizing the fundamentally interactionist perspective used in this paper toward identity dynamics (MacKinnon and Heise, 2010; see also Mead, 1934). Nevertheless, the identity dynamics detailed in our processual conceptualization of the actor play an essential role in the persistence and change of institutional arrangements.

\section{Implications of the processual actor conceptualization for service research}

Service research frequently discusses human actors, such as service providers, frontline employees, and customers, as a part of its frameworks and models. To date, however, no thorough theoretical conceptualization of human actors exists within the literature. In this paper, we augment S-D logic's institutionally constituted account of an actor by introducing two interrelated identity concepts - social identity and personal identity - with which we outline a processual view of the actor for service research (see Figure 2). This processual view is based on four processes that explicate both how institutional arrangements constitute the social identities that individuals internalize and how individuals enact social roles in particular ways to actualize their personal identities and, in doing so, participate in institutional reproduction and change.

\section{Figure 2.}

Personal identity as the outcome and enabler of the multiplicity of the social identities associated with overlapping service ecosystems

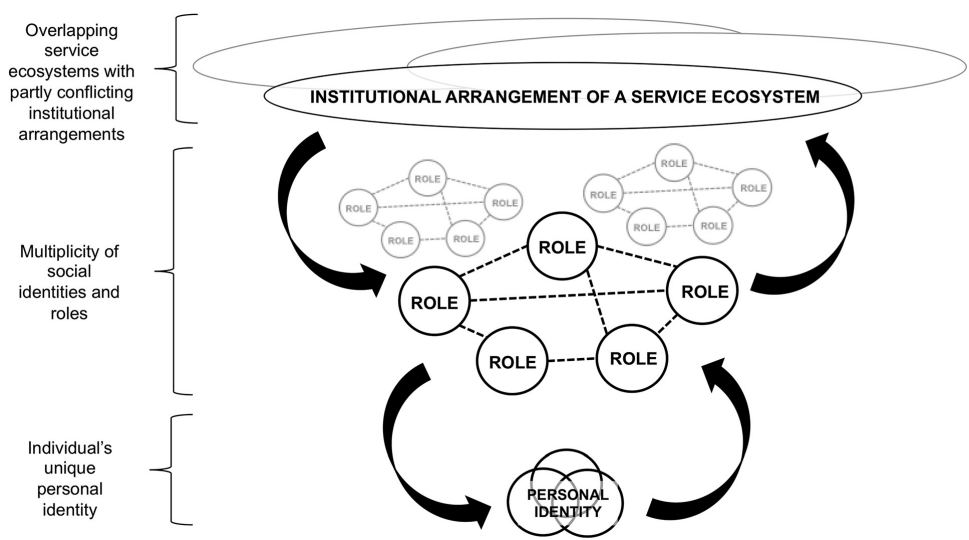


Figure 2 shows how the processual conceptualization of the human actor departs from the institutional view of S-D logic, according to which institutional arrangements guide, constrain, and coordinate value cocreation among resource-integrating actors (Vargo and Lusch, 2016). Specifically, the top half of the figure recognizes that the institutional arrangements associated with different service ecosystems comprise and constitute the interrelated social roles through which individuals engage in value cocreation in a particular context. The figure also depicts that through their interactive role performances, the actors reproduce (or change) the institutional arrangements that govern them. The institutionally actor in service research constituted roles also embody particular shared self-conceptualizations - that is, social identities - with which individuals make sense of themselves and of others as actors and guide their role enactment. The internalization of social identities thus binds individuals to particular roles, which works to maintain stability, predictability, and efficiency in collaborative value creation efforts.

The bottom half of the figure clarifies the central distinction made in this paper-the separation of the enduring yet evolving personal identity of an individual from the various social roles that the individual as an actor plays across the different contexts of her life. The personal identity of an individual is shaped through the internalization of multiple rolespecific social identities over her life course. This happens as the individual is socialized into new social contexts - first, in early childhood (through primary socialization) and later, to various specialized areas of social conduct (through secondary socialization). In turn, the personal identity thus formed directs the individual in selecting roles and performing them in particular ways as an actor. In this way, the personal identity shapes, for example, how the individual engages with a service process or the extent to which she seeks to maintain or change the prevalent roles and associated social identities in the situated instances of resource integration and value cocreation.

The processual conceptualization of the actor developed in this paper recognizes that the individual has little capacity to engage in value creation without being socialized into an institutionalized role that allows her to partake in value creation with others. Relatedly, the conceptualization emphasizes that actorhood is not an innate or static quality of humans. Instead, it is an outcome of the social processes that structure the roles through which individuals engage in value cocreation, as well as the personal identities that direct individuals in the selection and enactment of roles. Hence, humans as actors are in a constant state of becoming; they internalize the social identities and skills specific to the roles they play while simultaneously reproducing and potentially changing them through their interactions with others.

In addition to the importance of socialization, our conceptualization also stresses personal identity as the basis for individuals to adopt and perform their roles in particular, selfactualizing ways. Hence, being an actor is not about the mindless reproduction of institutionalized role-specific scripts. Instead, it is (at least partially) a conscious effort in fulfilling (and compromising on) one's personal needs and aspirations that are developed through the ongoing internalization of multiple institutionalized self-conceptualizations. This means that the ability of an individual to participate in a social context as a knowledgeable actor derives not just from socialization into that context; it also comes from the ability to draw connections to and borrow resources from adjacent contexts of social action and creatively recombine them into new social identities and shared material practices (MacKinnon and Heise, 2010).

\section{Implications for $S-D$ logic}

The processual view of the actor developed in this paper extends the institutional view of S-D logic by clarifying how the actor can be simultaneously considered an institutionally constituted resource integrator and a collection of (operant) resources, and a unique, value- 
JSTP

$30,4 / 5$

450

experiencing and value-defining beneficiary. Based on new insights from sociological and social-psychological theories on identity, this paper suggests that through socialization into various institutionally constituted contexts, actors learn multiple role-specific competences and social identities, which effectively make them capable actors and resource integrators. At the same time, these socialization processes shape individual's personal identity, based on which she not only directs her future actions but also experiences and determines the value of solutions. In our account, personal identities therefore constitute the motivational basis of actors to select particular social settings and roles and to enact them in particular ways in order to actualize their most valued and personally meaningful aspirations.

This idea sheds additional light on the contextual nature of value (Vargo et al., 2008) by suggesting that in addition to the institutional context (Chandler and Vargo, 2011; KoskelaHuotari and Vargo, 2016), value determination is significantly influenced by the distinct yet institutionally constituted personal identity of an individual. Moreover, the distinction between personal and social identity further explicates the importance of not defining human individuals as actors merely based on the specific roles they play at a certain point of time (e.g. service provider or customer); instead, the understanding of human actors also needs to include their distinct personal identities that orient them to enact specific value cocreation roles within and across the multiple service ecosystems and institutional arrangements that they occupy (Vargo and Lusch, 2016).

By analytically dissociating an individual's personal identity from the multitude of social identities she internalizes through primary and secondary socialization, this paper also advances S-D logic by elaborating the mutual constitution of actors and institutions. While S-D logic has explicitly drawn on Giddens (1984) in highlighting the endogenous and socially constructed nature of institutional arrangements, the idea of mutual constitution has remained rather vague and abstract in light of more specific inquiry. To address this, we explicate four processes that describe how the actor is simultaneously constituted by institutional processes and able to perform her roles in varying, even institution-changing, ways. This idea extends the metatheoretical conceptualization of S-D logic toward a midrange theory (Vargo and Lusch, 2017) by enabling a closer analysis of both the social construction and generative capacities of human actors within institutionally governed service ecosystems.

\section{Implications for investigating the actor in service research}

Beyond S-D logic, the processual view of the actor also contributes to the broader service literature by bringing roles back into the discussion as a key construct in understanding several service-related phenomena. Our conceptualization of the actor highlights roles and their associated social identities as the mediator between institutional arrangements and personal identities. This insight not only connects with the previous accounts of actors in the service literature, particularly studies based on role theory (e.g. Broderick, 1998; Solomon et al., 1985); it also moves beyond them by elaborating how such interactions are constituted within wider institutional arrangements and at the same time shaped by individuals playing their roles in particular and creative ways. Thus, our model can throw light on the dynamics through which particular service-related roles emerge, endure, and change through endogenous social processes.

In addition, whereas the role theory approach in service research has traditionally studied role dynamics with the (implicit) assumption that each actor only ever enacts a single role, the processual view highlights the complexity and multiplicity of the roles available to and played by individuals. Acknowledging personal identity as the basis for individuals' engagement with and performance of roles, we open up a host of exciting opportunities to provide a deeper understanding of the social dynamics in the service process. For example, the personal identity enables us to understand why and how individuals often have differing and even contradictory interpretations and expectations regarding a particular value cocreation context and its roles. It 
also allows us to develop solutions to such discrepancies before, during, and after the service process. Furthermore, we can investigate how the exposure of individuals to adjacent social contexts either enables or inhibits them to adapt their roles in the service process.
Rethinking the actor in service research

\section{Implications for understanding institutional change within service ecosystems}

Our processual actor conceptualization also throws additional light on the dynamics of institutional reproduction and change in service ecosystems (e.g. Koskela-Huotari et al., 2016; Siltaloppi and Wieland, 2018) in two ways. First, the current study extends the understanding of institutional change enabled by institutional complexity. As proposed by Siltaloppi et al. (2016), the multiplicity of institutional arrangements creates situations with contradictory institutional expectations and assumptions; these elevate conscious problem-solving and enable individuals to combine institutional resources from different contexts to create new solutions. The current work adds to this by suggesting that the extent to which the personal identities of individuals resonate with particular social identities over others influences their response to an institutionally complex situation. In particular, it affects whether they defend, blend, or seek to change current value cocreation practices (Pache and Santos, 2013). We also argue that the personal identity of individuals plays a central role in orienting them toward either institutional maintenance or change. For example, individuals differ in their orientation to complex situations; some are more conservative, whereas others are inclined toward the exploration of new opportunities.

Second, our focus on the identity dynamics opens another avenue for theorizing institutional change. This route departs from the observation that an institutional context may inhibit an individual from actualizing her personal identity through social action. Such a situation may amplify institutional contradiction as a person seeks to challenge and alter her institutionalized role performances. However, the possibility of creating alternative solutions, including new social identities and resource integration practices, within small and close-knit communities also exists. Within such communities, individuals have more latitude to envision completely new alternatives to the current social order and to develop new social identities and practices that support their self-actualization without being oppressed by the existing institutional arrangements (Berger and Luckman, 1967; Holland et al., 1998). As captured in the social movements literature (e.g. Benford and Snow, 2000), the groups based on new identities and practices can engage in various strategic actions to involve others in the movement and to institutionalize the new social order as a basis of collective action (see also Tolbert and Zucker, 1996). The importance of identity processes for institutional change can be seen in many social movements. For example, the feminist movement did not only openly criticize and challenge the practices of society that sustained the exclusion and oppression of women; it also involved extensive efforts to reconstruct and institutionalize the social and personal identities of women through new practices and symbolic actions.

\section{Directions for future research}

Our conceptual work opens several avenues for further theorizing and empirically investigating the role of identity dynamics in service research. First, the four processes explaining the dynamics between institutional arrangements, social identities, and personal identity open novel avenues for service research by developing a midrange theoretical account (Vargo and Lusch, 2017) of the social construction and generative capacities of human actors within institutionally governed service ecosystems. Under the S-D logic umbrella, this enables future research to investigate the impact of personal and social identities on the processes of resource integration, service exchange, value determination, and institutional reproduction and change. 
JSTP $30,4 / 5$

Second, the conceptualization of the actor based on identity dynamics can also inform future research on service encounters (Voorhees et al., 2017) and actor engagement (Storbacka et al., 2016). For example, the dynamics between social and personal identity may open interesting avenues for theorizing and empirically investigating service encounters and relationships from a processual perspective. In this approach, the actors mutually engage in behaviors through which they shape not only the shared social roles and associated identities but also their personal identities. Furthermore, research on actor engagement may find interesting research directions by adopting the processual conceptualization of the actor to extend the more systemic view on actor engagement (e.g. Brodie et al., 2019) and exploring the impact of the individuals' personal identities on the valence of their engagement (e.g. Li et al., 2018).

Third, our processual conceptualization of the actor is aligned with the cultural consumption approaches, within which identity is understood as a project that unfolds over time as consumers use mythic and symbolic resources from the marketplace to construct their identities (see e.g. Arnould and Thompson, 2005; Schouten, 1991). As such, this paper builds a bridge to continue the fruitful integration of insights from consumer culture studies to service research. The actor conceptualization developed here may contribute to the cultural consumption approaches by not taking the consumer role and the structuring influence of the marketplace as a starting point for individual's personal identity or actorhood. Instead, our study suggests that more attention is needed to the influence of multiple institutional arrangements and associated social identities in the development of a personal identity, including both market and nonmarket social identities. Conversely, future service research may exploit the insights from consumer culture studies regarding the development of consumer identities to further extend the understanding of the impact of identity processes to value cocreation.

Fourth, our framework points toward the importance of personal identity and individuallevel psychological processes as a basis for role-taking and social action. While this paper has purposefully remained in the social rather than psychological domain of theorizing, the latter can also offer interesting directions for future research. As detailed by MacKinnon and Heise (2010), for example, individuals are driven not only by their objectified self-conceptualizations in a cognitive sense (i.e. social identities) but also by their partially subconscious affective and bodily processes. These are likely to play an equally important role in shaping the behavior of individuals in service encounters and deserve additional theoretical attention to connect them with the current conceptualizations of actors and agency.

Fifth, our processual conceptualization encourages research to examine in depth the ways in which collectives of individuals constitute actors in the first place. This refers to how individuals, connected within institutional arrangements, produce shared goals and achieve coordinated behaviors through social interactions in a manner that gives rise to collective actors, for example, organizations and market communities. This line of inquiry could open avenues for extending the A2A view of S-D logic by explicitly considering the nature and agency of collective actors through the interplay among institutional arrangements, social groups, and individuals. In particular, we suspect that our conceptualization could be valuable in developing new insights into the social processes through which coordinated action emerges and is maintained within human groups. Here, research on group identities, such as organizational identity (e.g. Albert and Whetten, 1985), could be particularly useful. This literature theorizes the complex processes of identity formation and change (Gioia et al., 2013), as well as shows how the shared understandings among organizational members about who we are as an organization can be more powerful in directing and influencing the outcomes of change processes than formal strategies and hierarchical management are (e.g. Nag et al., 2007). Future research could, for example, investigate how organizational or other group identities influence the behavior of both frontline personnel and customers during the service process and thus the outcomes of collaborative value creation. 
Finally, our conceptualization focused on the human actor also sets a basis for extending theoretical work to nonhuman actors. With the recent interest in robots, AI, and other forms of technology as actors in service processes (e.g. Caić et al., 2018; Kaartemo; Helkkula, 2018; Robinson et al., 2019), this study can provide a point of reflection as research moves toward thinking about actors and agency as general phenomena pertaining to both human and nonhuman actors. As one potential starting point, differentiating human from nonhuman actors based on personal identity, which directs the agency of human beings across a multitude of roles, seems justified. However, there may be less radical difference between the two types of actors in the realm of social roles, in which the competencies to integrate resources and perform particular roles can reside both in human cognition and in nonhuman algorithms. Hence, the concept of social identity may prove useful in developing new insights into the nature of technologies as actors in service processes.

\section{Conclusion}

This paper sets out to advance the conceptualization of the human actor within S-D logic, in particular and in service research, in general. Drawing from identity theory and social constructionism, we introduced the concepts of social identity and personal identity, as well as the dynamics between the two to integrate institutional arrangements, roles within social groups, and individuals with particular personal identities into a processual conceptualization of the actor. Beyond the aforementioned specific contributions and future research avenues we outlined, our work calls for more attention to a processual view of actors, which seeks to understand the emergence, evolution, and change of actors embedded in multiple contexts of social action. Indeed, the processual view illuminates how individuals are complex assemblages of social roles and associated identities, as well as how they exist in a constant state of change (e.g. Abbott, 2016). While this indeterminacy and open-endedness of actors may be invisible in narrowly defined settings and short timeframes, considering change as the general state of affairs and stability as the temporary exception is reasonable (Padgett and Powell, 2012). In light of these observations, service research risks imposing too narrow and deterministic views on service phenomena if theorizing remains fixed to the stable aspects of objects, in this case, the actors, and the seemingly atomistic relations among them. Instead, we encourage research to not take the actors as given but to trace their emergence and constitution through a multitude of social processes. In this way, research can push beyond surface-level actions and outcomes to gain access to deeper transformational processes through which actors and institutional arrangements constitute each other, as well as to how these dynamics influence and play out in the context of service-related phenomena.

\section{Notes}

1. In the common language, the term "actor" is often used to refer to a person whose profession is acting in plays, films, or television shows. In this paper, the term refers generally to any "participant in an action or process" (Oxford Dictionary, 2019).

2. No laptops were harmed during the process of writing this article.

\section{References}

Abbott, A. (2016), Processual Sociology, University of Chicago Press, Chicago.

Akaka, M.A. and Chandler, J.D. (2011), "Roles as resources: a social roles perspective of change in value networks", Marketing Theory, Vol. 11 No. 3, pp. 243-260.

Akaka, M.A., Vargo, S.L. and Schau, H.J. (2015), "The context of experience”, Journal of Service Management, Vol. 26 Nos 6/7, pp. 206-223. 
JSTP

$30,4 / 5$
Ảkesson, M. (2011), Role Constellations in Value Co-creation: A Study of Resource Integration in an E-Government Context, $\mathrm{PhD}$, Karlstad University, Karlstad.

Alam, I. (2002), "An exploratory investigation of user involvement in new service development", Journal of the Academy of Marketing Science, Vol. 30 No. 3, pp. 250-261.

Albert, S. and Whetten, D.A. (1985), "Organizational identity", Research in Organizational Behavior, Vol. 7 No. 1, pp. 263-295.

Alexander, M., Jaakkola, E. and Hollebeek, L. (2018), "Zooming out: actor engagement beyond the dyadic", Journal of Service Management, Vol. 29 No. 3, pp. 333-351.

Archer, M.S. (1995), Realist Social Theory: A Morphogenetic Approach, Cambridge University Press, Cambridge.

Arnould, E.J. and Thompson, C.J. (2005), "Consumer culture theory (CCT): twenty years of research", Journal of Consumer Research, Vol. 31 No. 4, pp. 868-882.

Benford, R.D. and Snow, D.A. (2000), "Framing processes and social movements: an overview and assessment”, Annual Review of Sociology, Vol. 26 No. 1, pp. 611-639.

Berger, P.L. and Luckmann, T. (1967), The Social Construction of Reality-A Treatise in the Sociology of Knowledge, Anchor Books, New York, NY.

Biddle, B.J. (1986), "Recent developments in role theory", Annual Review of Sociology, Vol. 12 No. 1, pp. 67-92.

Bourdieu, P. (1990), The Logic of Practice, Polity Press, Cambridge, MA.

Broderick, A.J. (1998), "Role theory, role management and service performance", Journal of Services Marketing, Vol. 12 No. 5, pp. 348-361.

Brodie, R.J., Fehrer, J.A., Jaakkola, E. and Conduit, J. (2019), “Actor engagement in networks: defining the conceptual domain”, Journal of Service Research, Vol. 22 No. 2, pp. 173-188.

Burke, P.J. (1980), "The self: measurement implications from a symbolic interactionist perspective", Social Psychology Quarterly, Vol. 43, pp. 18-29.

Burke, P.J.(1991), "Identity processes and social stress", American Sociological Review, Vol. 56, pp. 836-849.

Čaić, M., Odekerken-Schröder, G. and Mahr, D. (2018), "Service robots: value co-creation and codestruction in elderly care networks", Journal of Service Management, Vol. 29 No. 2, pp. 178-205.

Cardinale, I. (2018), "Beyond constraining and enabling: towards new microfoundations for institutional theory", Academy of Management Review, Vol. 43 No. 1, pp. 132-155.

Chandler, J.D. and Vargo, S.L. (2011), "Contextualization and value-in-context: how context frames exchange”, Marketing Theory, Vol. 11 No. 1, pp. 35-49.

Farjoun, M. (2010), "Beyond dualism: stability and change as a duality", Academy of Management Review, Vol. 25 No. 2, pp. 202-225.

Feldman, M.S. and Pentland, B.T. (2003), "Reconceptualizing organizational routines as a source of flexibility and change”, Administrative Science Quarterly, Vol. 48 No. 1, pp. 94-118.

Friedland, R. and Alford, R.R. (1991), "Bringing society back in: symbols, practices and institutional contradictions", in Powell, W.W. and Dimaggio, P.J. (Eds), The New Institutionalism in Organizational Analysis, The University of Chicago Press, Chicago, pp. 232-263.

Giddens, A. (1984), The Constitution of Society: Outline of the Theory of Structuration, University of California Press, Berkeley, CA.

Giddens, A. (1991), Modernity and Self-Identity: Self and Society in the Late Modern Age, Stanford University Press, Stanford, CA.

Gioia, D.A., Patvardhan, S.D., Hamilton, A.L. and Corley, K.G. (2013), "Organizational identity formation and change", The Academy of Management Annals, Vol. 7 No. 1, pp. 123-193.

Greenwood, R., Oliver, C., Sahlin, K. and Suddaby, R. (Eds) (2008), The Sage Handbook of Organizational Institutionalism, SAGE Publications Inc., Thousand Oaks, CA. 
Grönroos, C. (1984), “A service quality model and its marketing implications”, European Journal of Marketing, Vol. 18 No. 4, pp. 36-44.

Helkkula, A., Kelleher, C. and Pihlstrom, M. (2012), "Characterizing value as an experience: implications for service researchers and managers", Journal of Service Research, Vol. 15 No. 1, pp. 59-75.

Holland, D., Lachiotte, W., Skinner, D. and Cain, C. (1998), Identity and Agency in Cultural Worlds, Harvard University Press, Cambridge, MA.

Kaartemo, V. and Helkkula, A. (2018), "A systematic review of artificial intelligence and robots in value co-creation: current status and future research avenues", Journal of Creating Value, Vol. 4 No. 2, pp. 211-228.

Koskela-Huotari, K., Edvardsson, B., Jonas, J.M., Sörhammar, D. and Witell, L. (2016), "Innovation in service ecosystems-breaking, making, and maintaining institutionalized rules of resource integration”, Journal of Business Research, Vol. 69 No. 8, pp. 2964-2971.

Koskela-Huotari, K. and Vargo, S.L. (2016), "Institutions as resource context", Journal of Service Theory and Practice, Vol. 26 No. 2, pp. 163-178.

Lave, J. and Wenger, E. (1991), Situated Learning: Legitimate Peripheral Participation, Cambridge University Press, Cambridge, UK.

Li, L.P., Juric, B. and Brodie, R.J. (2018), "Actor engagement valence: conceptual foundations, propositions and research directions", Journal of Service Management, Vol. 29 No. 3, pp. 491-516.

Lusch, R.F. and Vargo, S.L. (2006), "Service-dominant logic: reactions, reflections and refinements", Marketing Theory, Vol. 6 No. 3, pp. 281-288.

Lusch, R.F. and Vargo, S.L. (2014), Service-dominant Logic: Premises, Perspectives, Possibilities, Cambridge University Press, New York.

MacKinnon, N.J. and Heise, D.R. (2010), Self, Identity, and Social Institutions, Palgrave Macmillan, New York.

McCall, G.J. and Simmons, J.L. (1966), Identities and Interactions, Free Press, New York.

Mead, G.H. (1967/1934), Mind, Self and Society: From the Standpoint of a Social Behaviorist, The University of Chicago Press, Chicago, IL.

Nag, R., Corley, K.G. and Gioia, D.A. (2007), "The intersection of organizational identity, knowledge, and practice: attempting strategic change via knowledge grafting", Academy of Management Journal, Vol. 50 No. 4, pp. 821-847.

North, D.C. (1990), Institutions, Institutional Change and Economic Performance, Cambridge University Press, New York, NY.

Oliveira, P. and von Hippel, E. (2011), "Users as service innovators: the case of banking services", Research Policy, Vol. 40 No. 6, pp. 806-818.

Owens, T.J., Robinson, D.T. and Smith-Lovin, L. (2010), "Three faces of identity", Annual Review of Sociology, Vol. 36 No. 1, pp. 477-499.

Oxford Dictionary (2019), "Definition of actor in English", available at: https://en.oxforddictionaries. com/definition/actor (accessed 20 June 2019).

Pache, A.-C. and Santos, F. (2013), "Inside the hybrid organization: selective coupling as a response to competing institutional logics", Academy of Management Journal, Vol. 56 No. 4, pp. 972-1001.

Padgett, J.F. and Powell, W.W. (2012), The Emergence of Organizations and Markets, Princeton University Press, Princeton, NJ.

Parasuraman, A., Zeithaml, V.A. and Berry, L.L. (1985), "A conceptual model of service quality and its implications for future research", Journal of Marketing, Vol. 49 Fall, pp. 41-50.

Peters, L.D. (2012), "The role of the knowledgeable customer in business network learning, value creation, and innovation", Review of Marketing Research, Vol. 9, pp. 127-169. 
JSTP

$30,4 / 5$

Peters, L.D., Gassenheimer, J.B. and Johnston, W.J. (2009), "Marketing and the structuration of organizational learning", Marketing Theory, Vol. 9 No. 3, pp. 341-368.

Peters, L.D., Löbler, H., Brodie, R.J., Breidbach, C.F., Hollebeek, L.D., Smith, S.D., Sörhammar, D. and Varey, R.J. (2014), "Theorizing about resource integration through service-dominant logic", Marketing Theory, Vol. 14 No. 3, pp. 249-268.

Polese, F., Pels, J., Tronvoll, B., Bruni, R. and Carrubbo, L. (2017), “A4A relationships”, Journal of Service Theory and Practice, Vol. 27 No. 5, pp. 1040-1056.

Prahalad, C.K. and Ramaswamy, V. (2004), "Co-creation experiences: the next practice in value creation", Journal of Interactive Marketing, Vol. 18 No. 3, pp. 5-14.

Rajala, R., Gallouj, F. and Toivonen, M. (2016), "Introduction to the special issue on multiactor value creation in service innovation: collaborative value creation in service", Service Science, Vol. 8 No. 3, pp. iii-viii.

Robinson, S., Orsingher, C., Alkire, L., De Keyser, A., Giebelhausen, M., Papamichail, K.N., Shams, P. and Temerak, M.S. (2019), "Frontline encounters of the AI kind: an evolved service encounter framework", Journal of Business Research, doi: 10.1016/j.jbusres.2019.08.038.

Schouten, J.W. (1991), "Selves in transition: symbolic consumption in personal rites of passage and identity reconstruction", Journal of Consumer Research, Vol. 17 No. 4, pp. 412-425.

Scott, W.R. (2005), "Institutional theory", in Ritzer, G. (Ed.), Encyclopedia of Social Theory, SAGE, Thousand Oaks, CA, pp. 408-414.

Scott, W.R. (2014), Institutions and Organizations: Ideas, Interests, and Identities, Sage Publications, Thousand Oaks, CA.

Siltaloppi, J., Koskela-Huotari, K. and Vargo, S.L. (2016), "Institutional complexity as a driver for innovation in service ecosystems", Service Science, Vol. 8 No. 3, pp. 333-343.

Siltaloppi, J. and Wieland, H. (2018), "Institutional change in service ecosystems", in Lusch, R.F. and Vargo, S.L. (Eds), The SAGE Handbook of Service-Dominant Logic, SAGE Publications, London, UK, pp. 299-316.

Solomon, M.R., Surprenant, C., Czepiel, J.A. and Gutman, E.G. (1985), "A role theory perspective on dyadic interactions: the service encounter", Journal of Marketing, Vol. 49 No. 1, pp. 99-111.

Storbacka, K., Brodie, R.J., Böhmann, T., Maglio, P.P. and Nenonen, S. (2016), “Actor engagement as a microfoundation for value co-creation”, Journal of Business Research, Vol. 69 No. 8, pp. 3008-3017.

Stryker, S. (1968), "Identity salience and role performance: the relevance of symbolic interaction theory for family research", Journal of Marriage and Family, Vol. 30, pp. 558-564.

Stryker, S. (1980), Symbolic Interactionism: A Social Structural Version, Benjamin-Cummings/ Blackburn, Menlo Park, CA/Caldwell, NJ.

Stryker, S. (2008), "From mead to a structural symbolic interactionism and beyond", Annual Review of Sociology, Vol. 34 No. 1, pp. 15-31.

Stryker, S. and Burke, P.J. (2000), "The past, present, and future of an identity theory", Social Psychology Quarterly, Vol. 63 No. 4, pp. 284-297.

Swidler, A. (1986), "Culture in action: symbols and strategies", American Sociological Review, Vol. 51 No. 2, pp. 273-286.

Thornton, P.H., Ocasio, W. and Lounsbury, M. (2012), The Institutional Logics Perspective-A New Approach to Culture, Structure and Process, Oxford Univeristy Press, Oxford.

Tolbert, P.S. and Zucker, L.G. (1996), “The institutionalization of institutional theory”, in Clegg, S.R., Hardy, C. and Nord, W.R. (Eds), The Sage Handbook of Organization Studies, Sage, London, pp. 175-190.

Tronvoll, B. (2017), "The actor: the key determinator in service ecosystems", Systems, Vol. 5 No. 2, p. 38.

Tsushima, T. and Burke, P.J. (1999), "Levels, agency, and control in the parent identity", Social Psychology Quarterly, Vol. 62 No. 2, pp. 173-189. 
Vargo, S.L. and Lusch, R.F. (2004), "Evolving to a new dominant logic for marketing", Journal of Marketing, Vol. 68 No. 1, pp. 1-17.

Vargo, S.L. and Lusch, R.F. (2008), "Service-dominant logic: continuing the evolution”, Journal of the Academy of Marketing Science, Vol. 36 No. 1, pp. 1-10.

Rethinking the actor in service research

Vargo, S.L. and Lusch, R.F. (2011), "It's all B2B. . and beyond: toward a systems perspective of the market”, Industrial Marketing Management, Vol. 40 No. 2, pp. 181-187.

Vargo, S.L. and Lusch, R.F. (2016), "Institutions and axioms: an extension and update of servicedominant logic", Journal of the Academy of Marketing Science, Vol. 44 No. 4, pp. 5-23.

Vargo, S.L. and Lusch, R.F. (2017), "Service-dominant logic 2025”, International Journal of Research in Marketing, Vol. 34 No. 1, pp. 46-67.

Vargo, S.L., Maglio, P.P. and Akaka, M.A. (2008), "On value and value co-creation: a service systems and service logic perspective”, European Management Journal, Vol. 26 No. 3, pp. 145-152.

Voorhees, C.M., Fombelle, P.W., Gregoire, Y., Bone, S., Gustafsson, A., Sousa, R. and Walkowiak, T. (2017), "Service encounters, experiences and the customer journey: defining the field and a call to expand our lens", Journal of Business Research, Vol. 79, pp. 269-280.

Williams, J.A. and Anderson, H.H. (2005), "Engaging customers in service creation: a theater perspective", Journal of Services Marketing, Vol. 19 No. 1, pp. 13-23.

Wirtz, J., Patterson, P.G., Kunz, W.H., Gruber, T., Lu, V.N., Paluch, S. and Martins, A. (2018), "Brave new world: service robots in the frontline”, Journal of Service Management, Vol. 29 No. 5, pp. $907-931$.

\section{Corresponding author}

Kaisa Koskela-Huotari can be contacted at: kaisa.koskela-huotari@kau.se
For instructions on how to order reprints of this article, please visit our website:

www.emeraldgrouppublishing.com/licensing/reprints.htm

Or contact us for further details: permissions@emeraldinsight.com 